Asian J. Med. Biol. Res. 2020, 6 (1), 107-122; doi: 10.3329/ajmbr.v6i1.46485

\author{
Asian Journal of \\ Medical and Biological Research \\ ISSN 2411-4472 (Print) 2412-5571 (Online) \\ www.ebupress.com/journal/ajmbr
}

Article

\title{
Prevalence of bovine tuberculosis and its zoonotic implication in and around Bonga town, south west Ethiopia
}

\author{
Solomon Addisu* and Belay Abebe \\ Jimma University College of Agriculture and Veterinary Medicine, School of Veterinary Medicine, P. O. Box= \\ 307, Ethiopia
}

${ }^{*}$ Corresponding author: Solomon Addisu, Jimma University College of Agriculture and Veterinary Medicine, School of Veterinary Medicine, P. O. Box= 307, Ethiopia. Phone: +251917013104; E-mail: soladdisu04@gmail.com

Received: 27 February 2020/Accepted: 28 March 2020/ Published: 31 March 2020

\begin{abstract}
A cross sectional study was conducted from October 2013 to April 2014 G.C on 384 heads of dairy cattle and 107 cattle owners, in and around Bonga town, south west Ethiopia. Comparative intra dermal tuberculin test and questionnaire survey were carried out to determine the prevalence of bovine tuberculosis and to assess its zoonotic implication, respectively. Systematic random sampling technique was used to conduct the comparative intra dermal tuberculin test. Multivariate logistic regression model was used to analyze the data. Accordingly out of 384 heads of dairy cattle the overall prevalence was estimated to be $1.56 \%(6 / 384)$. Using 95\% confidence interval statistically significant variables were observed among sign of chronic cough with progressive wastage of body condition $(\mathrm{P}=0.043)$ and the origin of dairy cattle $(\mathrm{P}=0.039)$. While simple random sampling technique was used to select cattle owners for interview and 107 were participated. Analysis of retrospective data of six and half years on human TB collected from Bonga general hospital revealed significant level of TB cases. From the total TB patients, 56\% had pulmonary form of TB, while $44 \%$ had extra pulmonary form of TB patients registered. The result of the present study has revealed that relatively low prevalence of BTB in dairy cattle and poor awareness of the respondents on zoonotic implication of bovine tuberculosis. There should be segregation and practice of boiling of raw milk before consumption at home and awareness creation should be done for the whole society about bovine tuberculosis and its mode of transmission.
\end{abstract}

Keywords: BTB; dairy cattle; M. bovis; prevalence; risk factors; zoonoses

\begin{abstract}
1. Introduction
One of the regions of the world with rapidly growing human population is the Sub-Saharan Africa. The current data shows that human population is 500 million in Sub-Saharan region and it is expected to be 1300 million by the year 2025. By the year 2020, the Ethiopian population is estimated to be 139 million making the country the third most populous in Africa (WHO, 1999). As a result, the demand for animal products is increasing both in terms of quantity and quality, requiring the intensification of animal production integrated with genetic improvement. However, the animal diseases, shortage of feed and poor managements are some of the main constraints for the production system indicated, that bovine tuberculosis is becoming the main constraint for such strategies (WHO, 1993).

Bovine tuberculosis is a chronic infectious disease of animals characterized by the formation of granulomatous lesions in tissues and organs, more significantly in the lungs, lymph nodes, intestine and kidney including others. Bovine Tuberculosis is caused by M. bovis which is the most universal pathogen among Mycobacterium and closely related to the organism that causes avian TB (Mycobacterium avian), human TB, and Johne's disease (M. avian subspecies paratuberculosis). It affects many vertebrate animals of all age groups including humans. Although, cattle, goats and pigs are found to be most susceptible, while sheep and horses are showing a high natural resistance (Radostits et al., 2006; Thoen et al., 2006). Currently, the bovine tuberculosis in humans is becoming increasingly important in developing countries, as humans and animals are sharing the same micro-
\end{abstract}


environment and dwelling premises, especially in rural areas. At present, due to the association of Mycobacterium with the HIV/AIDS pandemic and in view of the high prevalence of HIV/AIDS in the developing world and susceptibility of AIDS patients to tuberculosis are high in Africa, with $90 \%$ of the population of Africa living in areas where neither pasteurization nor BTB control programmes occur (Amanfu, 2006).

Bovine tuberculosis is important in public health reasons as well as its detrimental effects on cattle production. Due to this, epidemiology of M. bovis is well documented in many countries and control and elimination strategies have long been implemented in the developed world by a policy based on systematic slaughter of infected animals, meat inspection in abattoirs and milk pasteurization, but reservoirs in wild life make complete eradication difficult. However, BTB is still common and widely distributed and largely uncontrolled in developing countries, which are unable to support the costs of test and slaughter policies and where BTB is often neglected and viewed as a secondary to the huge problem posed by the more readily transmissible human disease caused by M. tuberculosis (Cosivi et al., 1998). Because of the ability of BTB to infect humans and animals, its control is more difficult. The incidence of pulmonary tuberculosis caused by M. bovis is higher in farm workers than in urban inhabitants (OIE, 2009).

Mycobacterium bovis is a major cause of human gastrointestinal tuberculosis in developing countries (Bonsu et al., 2000). Unpasteurized contaminated milk and other secretions or tissues from animal hosts can serve as the source of infection for humans, milk through ingestion being regarded as the principal one (Grange, 1995). The bacterium usually enters through inhalation, ingestion of contaminated milk, water, or feed, multiplies locally, and causes primary lesions in the lungs and the lymph nodes that drain the respiratory tract (Ameni et al., 2012). In Ethiopia, where M. bovis infection is endemic, having the knowledge of distribution, prevalence, risk factors and zoonotic implication of the disease is a fundamental so as to set effective control strategy. Bonga town is one of the highland areas of South West Ethiopia where dairying is commonly practiced using small herd size. However, the extent of bovine tuberculosis in the area in both cattle and human was not known. Therefore, the objectives of this study were formulated:

E To determine the prevalence of bovine tuberculosis in individual dairy cattle level based on comparative intra-dermal tuberculin skin sensitivity test;

- To determine the risk factors associated with the occurrence of bovine tuberculosis in dairy cattle;

= To assess cattle owners' awareness on zoonotic implication of the disease through questionnaire survey and

= To assess the status of tuberculosis in humans in the study area through retrospective case book study from Bonga general hospital.

\section{Materials and Methods}

\subsection{Description of the study area}

The study was conducted from November 2013 to March, 2014 in and around Bonga town of South Nation Nationalities Peoples Regional State in South West Ethiopia. The town is located $450 \mathrm{kms}$ from Addis Ababa and $113 \mathrm{kms}$ from Jimma town with a longitude $36^{\circ} \mathrm{c} 0^{\prime} 2^{\prime \prime}$ to $36^{\circ} \mathrm{c} 0^{\prime} 5^{\prime \prime}$ west and latitude $7^{\circ} \mathrm{c} 2^{\prime} 1^{\prime \prime}$ to $7^{\circ} \mathrm{c} 4^{\prime} 9^{\prime \prime}$ north and an altitude of 1604 to 1835 meters above sea level. Bonga town has received an average annual rainfall ranging from $3212.3 \mathrm{~mm}$ to $4159 \mathrm{~mm}$ and an average annual temperature ranging from 11.96 degree Celsius to 26.99 degree Celsius. The agro ecological zone is divided into low land (15.3\%), High land (10.3\%) and midland (74.4\%). The major economic activities of the population were depends on farming crops and livestock production. Small numbers of improved breed dairy cattle were found in urban and peri-urban areas; mainly local breeds are found, grazing in communal land under traditional animal husbandry system. Bonga town is one of the potential areas in livestock resources, but a lot of constraints are wide spread for the reduction of animal's production systems (Kafa Zone Agriculture and Rural Development Department, 2012).

\subsection{Study population and sample size determination}

The study population was comprised of indigenous (local), cross and exotic breeds of dairy cattle. Cattle found in and around Bonga town was the target animals. The livestock population of the area comprised about 52,230 cattle, 28,091 sheep, 19,603 goats, 12,061 equines and 46,896 Poultry (Kafa Zone Agriculture and Rural Development Department, 2012). The total numbers of animals required for the study was calculated based on the formula given by Thrusfield (Thrustfield, 2007). Since there was no previous study in the prevalence of bovine tuberculosis in the area, $50 \%$ prevalence was taken to calculate the sample size and it was calculated at 95\% confidence interval and a desired accuracy level of $5 \%$.

$$
\mathrm{N}=\frac{(1.96)^{2} \mathrm{P}}{\mathrm{d}^{2}} \frac{\exp }{\left(1-\mathrm{P}_{\mathrm{exp}}\right)}
$$


Where $\mathrm{N}=$ sample size, $\mathrm{d}=$ desired absolute precision $(0.05), \mathrm{P}_{\mathrm{exP}}=$ expected prevalence $(50 \%)$, thus the desired sample size for $\mathrm{p}=0.5$ will be $\mathrm{n}=384$. Therefore, a sample size of 384 cattle was examined in this study.

\subsection{Ethical consideration both in human and in animal during the study}

The purpose of the study was explained to the owners to be involved in the study. The owners has were informed, when their animals were found BTB positive and were advised to take some measures of disease prevention and control such as separated TIDT tested positive from the rest of the herd to avoid the spread of the infection to others and isolation of calves immediately after birth from TB infected cattle and practice of boiling the milk of infected cattle before selling and consumption at home, avoid consumption of raw meat, and avoid close contact with TB infected cattle, specially children, pregnant women and other immune compromised peoples.

\subsection{Study design and sampling techniques}

A cross-sectional study was conducted from November 2013 to March 2014 on 384 heads of dairy cattle, in and around Bonga town, South West Ethiopia, to determine the prevalence of BTB using CIDT test. During the study time, the study cattle were selected purposively. Since, study animals were dairy cattle (females) only, because this disease was routinely transmitted to humans by consumption of raw dairy products. And individual dairy cattle were selected systematic randomly sampling technique for the study.

Physical examinations of animals were carried out before the cattle were injected with PPD. For this study, cattle were grouped in to age groups by looking an eruption of one or more teeth and were classified in this study as young from 6 months to 3 years, adult from 3 to 7 years and old above 7 years. Instead of breeds group: cattle were classified as local, cross and exotic breeds. The body condition of each sampled cattle was recorded using the guide line established by Nicholson and Butterworth (1986) and aggregated in to three groups (as poor (1-3), medium (4-6) and good (7-9)) in this study. According the management practice of dairy production; were classified as extensive, semi-intensive and intensive. Based on their origin they were obtained dairy cattle were classified as born at home and purchased from different local markets brought from unknown sources.

Based on history of the dairy cattle for the presence and absence of chronic cough with progressive wastage of body condition for more than six months and observation of respiratory symptoms during test carried out cattle were classified as do have sign of chronic cough and do not have sign of chronic cough with progressive wastage of body condition. Instead of lactation status; classified as lactating and non-lactating (included heifers) through asking the owner and observation of mammary gland, but instead of reproductive status classified as pregnant and non-pregnant (included heifers) through history of conception date of the cattle from the owners' and through rectal palpation of the uterus to diagnose pregnancy before test was performed and registered on the format of record sheet.

\subsection{Methodology of data collection}

\subsubsection{Comparative Intra Dermal Tuberculin (CIDT) Test}

This test was performed in dairy cattle above six months of age, excluding those in late pregnancy and recently calved calf/heifers, because false negative reaction may occurs in these animals. The comparative intra-dermal tuberculin test was performed on the mid-neck, but the test was also performed in the caudal fold of the tail. The skin of the neck is more sensitive to tuberculin than the skin of the caudal fold, for this reason the skin of the neck was selected. CIDT test is used to differentiate between animals infected with $M$. bovis and those sensitized to bovine tuberculin as a result of exposure to other Mycobacterium.

The injection sites was first clipped and cleaned. A fold of two sites on the skin of the mid-neck $12 \mathrm{~cm}$ apart were shaved and the skin thickness was measured in millimeters with calipers before the injection of tuberculin. In youngs in which there is no room to separate the sites sufficiently on one side of the neck; one injection was made on each side of the neck at identical sites in the centre of the middle third of the neck and recorded on data collection format sheet. Aliquots of $0.1 \mathrm{ml}$ of $30000 \mathrm{IU} / \mathrm{ml}$ bovine PPD (Mycobacterium bovis strain AN5, Bovitubal Bioveta, Czech Republic and Mycobacterium avium strain and $0.1 \mathrm{ml}$ of $30000 \mathrm{IU} / \mathrm{ml}$ avian PPD (Mycobacterium avium D4ER strain, Avitubal Bioveta, Czech Republic) were injected into the dermis at these sites. A short needle, bevel edge outwards and graduated syringe charged with tuberculin attached was inserted obliquely in to the deeper layers of the skin. Then a dose of tuberculin was injected. A correct injection was confirmed by palpating a small pea-like swelling at each site of injection. The skin-fold thickness of each injection site was re-measured 72 hours after injection and recorded also on the same data collection format sheet. The results were interpreted as described by OIE (2004) protocol: When the change in skin thickness 
increased at both sites, the difference between the two changes was considered. Thus, if the increase in skin thickness at the injection site for the bovine PPD-b was greater than the increase in skin thickness at the injection site for the avian PPD-a and $\Delta \mathrm{B}-\Delta \mathrm{A}$ was less than $1 \mathrm{~mm}$, between $2 \mathrm{~mm}$ and $4 \mathrm{~mm}$, or $4 \mathrm{~mm}$ and above, the cattle were classified as negative, doubtful and positive for bovine tuberculosis, respectively.

\subsubsection{Questionnaire survey}

The objective of the questionnaire survey was explained to the participants before start of the interview. A questionnaire survey with open and closed questions was used amongst the owners' whose dairy cattle were tested and who were willing to participate in the survey. A predesigned questionnaire was administered to cattle owners whose cattle's were tested. The owners' or one from the member of the households were interviewed in their local language at the time the CIDT test was conducted. The questionnaire was developed in English and translated into Kafigna language for participants. The questionnaire was basically divided into three parts comprising (1) general information about the respondents, (2) risk factors for the occurrence of BTB in dairy cattle husbandry practices, (3) knowledge of respondents about zoonotic implication of BTB included their milk and meat consumption practices, their association with cattle, their knowledge on transmission routes of BTB from infected cattle to humans, history of tuberculosis upon them and other relevant information's related to tuberculosis were interviewed.

\subsubsection{Retrospective case study of tuberculosis in human}

Assessed the status of tuberculosis in humans in the study area registered from September 1, 2000 to February $30,2006 \mathrm{E} . \mathrm{C}$ or six and half years through retrospective case book study of recorded data in Bonga general hospital.

\subsection{Data management and statistical analysis}

Before performing of the analysis the variables were grouped in to: dependent: CIDT test results which are categorized as positive and negative; independent variables: age, breed, body condition, management system, origin of cattle, sign of chronic cough with progressive wastage of body condition, lactating status and reproductive status of dairy cattle. All the collected data was entered through Microsoft Excel 2007 program and data analysis was performed with Logistic regression using STATA 12 statistical computer software. A p-value less than 0.05 were considered statistically significant with 95\% confidence interval. Odds ratio (OR) was calculated to assess the strength of association of different risk factors to the prevalence of bovine tuberculosis( BTB), while analyzing the data, doubtful results were taken as negative.

\section{Results and Discussion}

\subsection{Overall prevalence}

A total of 384 cattle were tested for tuberculosis and the results of the comparative intra dermal tuberculin test (CIDT) in cattle of the study revealed that $1.56 \%$ (6/384) was found TB infected without considering doubtful reactors as positives.

\subsection{Risk factors associated with bovine tuberculosis}

Multivariate logistic regression analysis was used to assess the relationship between risk factors and CITD test reactors in this study. Among the risk factors assessed, the origin of dairy cattle obtained or introduced new dairy cattle was statistically significant $(\mathrm{OR}=13.575 ; \mathrm{p}<0.039)$. The analysis showed that purchased cows (new introduced) had a higher risk (13 times) to be a CIDT test reactor in large than born at home. Association was observed between positive reactors and the history for the presence of chronic cough with progressive wastage of body condition for more than six months $(\mathrm{OR}=7.688$; $\mathrm{p}<0.043)$. The analysis also showed that presence of chronic cough with progressive of body wasted cows had a higher risk ( 7 times) to be a CIDT test reactor in large than absence. However, the rests assessed as risk factors in this study were no statistically significant difference between/among them (age, breed, management system, body condition, lactating status and reproductive status) as depicted in Table 2 below.

\subsubsection{Prevalence study}

The comparative intra dermal tuberculin test is the internationally recognized standard method to identify infection with $M$. bovis, and it is currently the most widely applied screening test for detecting BTB in living animals (Mananghan et al., 1994). Bovine tuberculosis is important in public health reasons as well as its detrimental effects on cattle production. Different researchers in different geographical areas have reported its 
prevalence and public health importance in different parts of Ethiopia. The prevalence may however vary from country to country or even within a country. The overall individual prevalence of bovine tuberculosis using the comparative intra dermal tuberculin test recorded in this study was $1.56 \%(6 / 384)$ as presented in table1 above. This result was similar with $1.6 \%$ on individual cattle reported by Ameni and Laval (Ameni and Laval, 2004) in Boji District of western Ethiopia.

However, this result was lower than results previously reported from different parts of Ethiopia the prevalence of BTB in individual cattle: $11 \%$ reported by Ameni and Erkihun (2007) in Adama town; $7.3 \%$ reported by Sisay et al. (2013) in Tigray region; 3.4\% reported by Redi (2003) in Asella town; 11\% indicated by Mamo et al. (2013) Afar pastoralists in Ethiopia; 5.9\% indicated by Amenu et al. (2010) in Arsi-Negele Districts in Ethiopia and $11.3 \%$ recently reported by Fikre et al. (2014) in and around Mekele town, Northern Ethiopia. The lower result of the current study could be due to different factors such as delayed hypersensitivity may not develop for a period of 3-6 weeks following infection, kind of test used, sample size, geographic distribution, breed, age and management practice of tested cattle. Also the number of cattle kept under each house hold is small in number due to the study was carried in urban and per urban in which the transmission rate of the disease is dependent on herd size as stated by O'Reilly and Deborn (1995). Besides, the result may also be related to individual variation of anergy reactivity to tuberculin is a major limitation of intra-dermal tuberculin (CIDT) test. Intensity of reaction may vary between individual and absence of reaction (anergy) is common especially in case of inter-current disease occurrence and length of infection with M. bovis.

Another reason for the lower result of this study observed was dairy cattle owners kept on communal grazing land, predominantly Zebus cattle, while culturally the peoples belief that if the high productive and expensive cows (Cross and Holstein breeds) seen by bad luck/evil eye strangers or even neighbors causing them to become drop in milk production, sick or dying as a consequence, they were often kept alone in a secluded shed in the house compound and fed and milked there. This practice likely reduces the risk of contracting the disease from the animals of other owners and thus limits spread of disease BTB in the area. Also may be associated with the infections of cattle with gastro-intestinal parasite such as Fasciolosis and strongyle compromised the immune response to tuberculin test by shifting the immune from Th1 to Th2 response there by promoting the emergence of false negatives and also false negative responses are sometimes seen soon after infection, in the late stages of the disease and in animals with poor immune responses as reported by Ameni and Medhin (2000). The result of current study was relatively greater than prevalence of individual cattle previously reported from different areas. From Ethiopia, $1.0 \%$ by Tamiru et al. (2013) in Ambo and Toke Kutaye districts, $0.8 \%$ reported by Tschopp et al. (2010) from Hamer Woreda, South Omo and outside of Ethiopia, 1.3\% reported by Inangolet et al. (2008) from Uganda. The difference in prevalence of BTB might be related to influence by breed of cattle and type of farming and gathering of animals at grazing and watering areas and the difference might be related to the epidemiological factors that favor the transmission of BTB, which include herd sizes, communal grazing and watering of diverse species of animals (Mamo et al., 2013).

In current study, there was no statistically significant difference between/among age assessed as risk factors in the overall prevalence of BTB in Table 2 above. Absence of significant difference among age groups is in line of agreement with reported from Akaki, Ethiopia and from Arsi-Negele by Amenu et al. (2010). This might be small number of tested dairy cattle in the present study. However, the disease proportion is more prevalent in old (age above 7 years) than adult (age between 3 and 7 years) and young (age between above 6 months and 3 years) in the current study. Old age dairy cattle were ( $\mathrm{OR}=3.418 ; \mathrm{P}>0.511)$ presented in table 2 above, 3 times more reactive to intra-dermal tuberculin test than those of young cattle in this study. This could be because as the age increases the probability of acquiring TB infection also increases (Barwinnek and Taylor, 1996). As previously indicated by other worker Ameni (1996), the same result were observed for the reactivity of animals to tuberculin test for increase with age due to chronic nature of the disease. According to Nega et al. (2012), analysis for the effect of risk factors revealed that the animal level of prevalence of BTB increased with age up to the age of 7 years, and was then observed to decrease slightly. Fewer reactor animals were recorded in the younger age groups and reactivity to the CIDT test increased with age, up to six years of age, after which it declined according with findings by researchers Asseged et al. (2000). This study showed differences in prevalence in breeds assessed as risk factors. High proportion of prevalence of BTB was recorded in exotic breed 5.9\% (1/17) as compared to zebu breeds $0.5 \%$ (1/199) and their crosses $2.4 \%$ (4/164) in Table 2 above; which is in line of agreement with earlier reported by Kiros (1998). The probable reason could be genetically improved cattle may suffer more severely from deficient housing and malnutrition; subsequently; become more prone to infection than local breeds. On the other hand, zebu cattle are relatively resistant to BTB than European breeds (Radostits et al., 2006). 
The current study showed, no association was observed between positive reactors and management system for the occurrence of BTB had no observed differences as presented in table 2 above. This could be due to small number of sample size as compared with other studies in different areas, absence of medium or large sized intensive and semi intensive dairy farms in the study area. Also, body condition of the cattle was no statistically significant assessed as risk factors in the overall prevalence of BTB. This is similar with other studies conducted in different parts of Ethiopia; in Adama town reported by Ameni and Erkihun (2007); in the pastorals in Oromia region, Southern Ethiopia; in Afar Region of pastoral and agro-pastoral reported by Mamo et al. (2013), there was no statistically significant association between body condition score and tuberculin skin test positivity. The result showed, dairy cattle under medium body conditioned reacted $(\mathrm{OR}=8.317 ; \mathrm{P}>0.271)$ presented in Table 2 above, 8 times to intra-dermal tuberculin test better than those of with poor body conditioned cattle and 2 times more reactive to intra-dermal tuberculin test than those which were have good body conditioned animal (good, $\mathrm{OR}=6.959 ; \mathrm{P}>0.348)$ presented in Table 2 above. According to Barwinek and Taylor (1996) animal with poor body condition may undergo the state of anergy (unresponsive state) due to immune-compromization related to certain stress factors. As a result of these cattle could fail to respond to the tuberculin test, even though, they might be infected with BTB leading to positive result.

In this study, the origin of dairy cattle was statistically significant assessed as risk factor in the overall prevalence of BTB. The Prevalence of bovine TB was significantly higher in purchased (introduced new) dairy cattle $(\mathrm{OR}=13.575 ; \mathrm{P}<0.039)$ than born at home. Dairy cattle purchased or introduced from different local markets of unknown origin brought were 13 times more reactive to intra-dermal tuberculin test than those which were born at home in this study. This could be associated that the farmers/owners of the cattle who were restocked or replaced his/her herd by purchasing cattle from unknown sources brought without requesting the cattle should be tested for BTB and also they were not aware the risk involved in trading cattle as they spread BTB by such unrestricted animal movements in the area. In our country, there were no practices for premovement testing of cattle for TB and also there were no practices for only purchase dairy cattle with a negative tuberculin test. Like most Mycobacterium, M. bovis multiplies slowly; cattle with bovine TB may appear perfectly healthy during the early stages of the disease; so peoples only seen the physical appearance of the cattle during purchasing. In addition this, insufficient AI services in the area to improve the genetic makeup and productivity of the local breeds and lack of livestock research centers nearby the area to distribute the improved breeds of cattle to the society; these were predisposing factors for seeking of peoples to have got improved breeds of dairy cattle without knowing the origin of cattle in the study area.

Similarly, statistical significance was observed in dairy cattle which had a sign of chronic cough or symptom of respiratory tract especially coughing is most common in the morning or in cold weather for more than six months of the cattle history with progressive wastage of body condition $(\mathrm{OR}=7.688 ; \mathrm{P}<0.043)$. This is in line of agreement with reported by Sisay et al. (2013), the presence of chronic cough was found the major risk factor significantly associated with the occurrence of tuberculosis among the study animals. This is could be due to dairy cattle those were positive for TB might be affected by lung TB or pulmonary forms rather than extrapulmonary TB. As stated by Radostits et al. (2006), pulmonary involvement of tuberculosis is characterized by a chronic cough due to bronchopneumonia. In contrast, no association was observed between positive reactors and in lactating status (lactating and non lactating dairy cows included heifers) and reproductive status (pregnant and non pregnant cows included heifers) assessed as risk factors in this study. Absence of association in this study might be related to the small number of the sample size.

\subsubsection{Questionnaire survey}

Human beings acquire $M$. bovis infection primarily by ingestion of the agent in milk and milk products. Ashford et al. (2001) indicated that milk is still regarded as principal vehicle for transmission of M. bovis to human in countries where bovine TB is not controlled. Ingestion of raw milk and other dairy products are more often associated with extra-pulmonary TB. In the situation where $M$. bovis is found in cattle the communities in general and dairy workers particularly are at high risk of infection, not only due to raw milk consumption, but also due to inhaling the bacilli directly from the infected dairy cattle due to closed physical contact and the animal during night sharing same shelter. Also Cosivi et al. (1998) indicated that PTB as well as EPTB cases of human TB of animal origin will continue to public importance especially in areas where the prevalence of infection is high in cattle and where raw milk and its products are commonly consumed. Kleebreg (1984), indicated that one cow with TB mastitis can excrete enough viable tubercle bacilli to contaminate the milk of up to 100 cows when the milk pooling and bulk of transportation used. This is a great public health hazard in the town like Bonga where the consumers buy milk and milk products directly from local market in which the milk is ingested without heat treatment. 
The results of the questionnaire survey conducted in and around Bonga town showed that in line of their feeding habit, 55.1\% (59/107) respondents have the habit of raw milk consumption; 57\% (61/107) were knew the side effect of raw milk consumption as it transmit diseases as presented in table 3 above. This is similar with 55.4\% of the respondents consumed raw milk reported by Teschop et al. (2010), in Arsi Zone, Oromia region. Similarly, high proportion of cattle raising families were reported to have the habit of drinking raw milk and milk products by studies conducted in selected sites of Ethiopia by Ameni and Wudie (2003); Ameni et al. (2003a). Consumption of unpasteurized fresh and soured milk potentially infected with M. bovis was found to cause milk borne infection with BTB. Such risk was reported to be the main cause of EPTB and is high in areas where BTB is common and uncontrolled (Lee and Mills, 2000). Assessment of meat consumption habit of the respondents through questionnaire survey showed that, 35.5\% (38/107) and 64.5\% (69/107) of them consumed raw meat and cooked meat, respectively. From total respondents, 58.9\% (63/107) had the knowledge of its side effect.

Higher number of respondents had no detailed and accurate knowledge about bovine tuberculosis was observed in this study, could also magnify the public health implication of BTB. Only $21.5 \%$ (23/107) of the dairy cattle owners interviewed understood that bovine TB is a cattle disease and were aware that it could be a zoonotic disease, while $78.5 \%(84 / 107)$ of the respondents did not know as cattle could have TB and did not had information that it could be a zoonotic disease. Similarly, different studies conducted in different parts of Ethiopia and in different African countries revealed low level understanding of the cattle owners about BTB and its zoonotic importance. According to the study carried out in Jimma town, only $25.7 \%$ by Tigre et al. (2011); only $37.1 \%$ reported by Tirsit et al. (2013) in Mana and Limmukoso Districts of Jimma Zone; knowledge of cattle owners about BTB in Wuchale-Jida district, Ethiopia showed that only 38.3\% (36/94) of the respondents knew that cattle can have tuberculosis reported by Ameni et al. (2003a) and only 35\% of the respondents knew about bovine TB and its means of transmission in Adama town by Amen and Erkihun (2007). A study conducted by Munyeme et al. (2010) in Zambia, among the cattle owners that were interviewed, only 39.6\% (25/64) had heard of bovine tuberculosis, or tuberculosis in cattle. In contrast, study reported from Cameroon by Ndukum et al. (2010) which indicated $81.9 \%$ of cattle handlers knew BTB, however with $67.9 \%$ of them knew as BTB is zoonotic.

Assessment of the knowledge of dairy cattle owners about its mode of transmission (via close contact, via inhalation and via consumption of raw milk and meat from TB infected cattle), an average of $23 \%$ of the respondents had knowledge about transmission through fore mentioned routes, but $77 \%$ having no basic knowledge of its route of transmission presented in table 3 above. This result is higher than a study conducted by Munyeme et al. (2010) in Zambia, only 7\% (5/64) had an idea on how the disease is spread with 92.9\% (59/64) having no basic knowledge of its transmission. Poor awareness of the respondents were seen about the transmission routes of the disease from cattle to human, but keeping cattle in close proximity to their house and calves in their house is a common practice of households in this study area. $18.8 \%(20 / 107)$ respondents share a single living house with cattle and other domestic animals. This indeed can facilitate zoonotic impact of the disease not only bovine TB, but also other zoonotic diseases like brucellosis. This findings difference observed in general may showed that the presence of knowledge gap between dairy cattle owners from place to place and between city and residence. Such variability could be due to difference in the participants' educational status, their access to media and other public health information services, lack of basic knowledge to identify tuberculosis in human of animal origin and tuberculosis of human of human origin and the prevalence of the disease in the specific area. Conditions such as customs of consuming raw milk, keeping cattle in close proximity to the owner house and using cow dung for plastering wall or floor and as source of energy for cooking do exacerbate the chance of spread of tuberculosis as zoonosis in Ethiopia.

In present study, 10.3\% (11/107) of the respondents had found tuberculosis. The results of the current study was lower than reported from Northwest Ethiopia by Tamiru et al. (2013), 14.3\% (11/77) of the participants had found tuberculosis. Among the respondents, 2.8\% (3/107) had found HIV/AIDS; from these, 33.3\% (1/3) or from total participants, $0.9 \%$ (1/107) of the respondent was HIV/AIDS patient positive for tuberculosis as presented in table 3 above. This might be due to, tuberculosis and other Mycobacterium infections are major opportunistic infections in HIV/AIDS infected individuals, while HIV/AIDS is a major predisposing factor for tuberculosis, including reactivation of disease. The current spreading pandemic of HIV/AIDS infection in developing countries, especially where bovine TB is prevalent both in domestic and wild animals, posses an additional serious public health treat (Grange, 1995). In Ethiopia, the first case of HIV/AIDS was reported in 1985, while recent studies have shown a prevalence rate of $4.4 \%$ for HIV/AIDS in adults aged 15 to 49 years with the vast proportion having extra pulmonary tuberculosis (WHO, 2005). The influence of respondent's age and educational status on their knowledge of bovine TB is a cattle disease and is a zoonotic disease parameter is 
considered in this study. A significantly $(\mathrm{OR}=1.2456$; $\mathrm{p}<0.049)$ larger proportion of $(32.4 \%)$ young respondents had aware for bovine TB is a cattle disease and it is zoonotic than (15.7\%) adult respondents. According their education status; illiterates were 3 times $(\mathrm{OR}=3.15 ; \mathrm{P}<0.168)$ did not know that $\mathrm{BTB}$ is a cattle disease and it is zoonotic than higher institution attended. Age, sex and education status of the respondents had no statistical significant on their awareness of the knowledge on modes of bovine TB could transmitted from TB infected cattle to human. Illiterates were 6 times $(\mathrm{OR}=6.0198 ; \mathrm{p}<0.107)$ and 7 times $(\mathrm{OR}=7.18799 ; \mathrm{P}<0.07)$ at risk of contracting tuberculosis through close contact and through inhalation of infective droplets from TB infected cattle than higher institution learned, respectively. But over half of the respondents did not know the transmission routes of bovine TB to human. The associations between awareness of the respondents versus their age, sex and education status were summarized above in tables from 4 to 7 .

\subsubsection{Retrospective study of tuberculosis in human}

According the result of retrospective case book study of human tuberculosis data registered for previous six and half years (started from September 1, 2000 to February 30, 2006 E.C) obtained in Bonga general hospital showed that an average of 268 TB suspected patients were found to visit the hospital in a year. A total of 1605 cases registered in TB case books previous six and half years, 49\% (786/1605) were smear positive for both forms of TB cases in male and female, while 51\% (819/786) were found smear negative for pulmonary tuberculosis in both sex. From smear positive patients, 56\% (441/786) had pulmonary form of TB cases, while $44 \%$ (345/786) had extra pulmonary form of TB cases were found presented in table 8 above. This data showed, the number of EPTB 44\% (345/786) were higher than a study conducted in selected sites East Showa, Ethiopia, out of 7138 human patients with tuberculosis, only $38.4 \%$ were found to have EPTB. But relatively lower than a study conducted in Jimma specialized hospital by Tigre et al. (2011), out of 8162 cases registered, only $48.4 \%$ of them had extra-pulmonary form, while $51.6 \%$ of the cases were found to be pulmonary form of TB.

According patients' sex, 57\% (447/786) were male patients; from male patients, 57.5\% (257/447) had pulmonary form of TB and 42.5\% (190/447) had extra pulmonary form of TB, while 43\% (339/786) were female patients, from female patients 54.3\% (184/339) had pulmonary form of TB and $45.7 \%$ (155/339) had extra pulmonary form of TB presented in table 8 above. From this study, the number of pulmonary form of TB was relatively higher than extra pulmonary form. Besides, the proportion of female affected with extra pulmonary TB was relatively greater than male patients'. This might be related with the traditional view of the society, females were highly exposed to contact with dairy cattle during milking and keeping in the pasture than males and mostly females sharing single living house with cattle were also another factor. Ashford et al. (2001), reported that the proportion of which BTB contributes to the total tuberculosis cases in humans depends on the prevalence of the disease in cattle, consumer's habit, socio-economic conditions, level of food hygiene and medical prophylaxis measures in practice. As stated by Radostits et al. (2006), M. bovis can be responsible for 5 to $10 \%$ of human tuberculosis with higher rates in children in some areas. This survey suggested that many dairy cattle owners sold their milk to restaurants and cafeteria, but it is difficult to estimate how much of that milk pasteurized or boiled before consumption. Overall, the available information suggests that a significant volume of milk may be distributed without being pasteurized. As stated by Lee and Mills (2000), consumption of unpasteurized fresh and soured milk potentially infected with M. bovis was found to cause milk born infection with BTB; such risk was reported to be the main cause of extra pulmonary tuberculosis and is high in areas where bovine TB is common and uncontrolled. As reported by Robertson and Assefa et al. (2006), 30\% of all TB cases in Ethiopia are Extra Pulmonary tuberculosis (EPTB), predominantly lymphadenitis.

Table 1. Results of comparative intra dermal tuberculin test.

\begin{tabular}{llll}
\hline CIDT test & No. of cattle tested $(\mathbf{n}=\mathbf{3 8 4})$ & Percent $(\boldsymbol{\%})$ & $\mathbf{9 5 \%}$ CI \\
\hline Positive & 6 & 1.56 & $0.00575-0.03697$ \\
Negative & 378 & 98.44 & \\
Total & $\mathbf{3 8 4}$ & $\mathbf{1 0 0}$ & \\
\hline
\end{tabular}


Table 2. CIDT result for bovine tuberculosis and associated risk factors using multivariate logistic regression analysis.

\begin{tabular}{|c|c|c|c|c|c|c|}
\hline Variables & No. of cattle Tested & No. of positive & Percent & Odds ratio & P-value & $95 \% \mathrm{CI}$ \\
\hline \multicolumn{7}{|l|}{ Age } \\
\hline Young & 72 & 1 & 1.4 & Ref* & - & - \\
\hline Adult & 207 & 3 & 1.5 & 1.31255 & 0.801 & $0.1591177-10.82713$ \\
\hline Old & 105 & 2 & 2.0 & 3.418969 & 0.511 & $0.0875545-13.5094$ \\
\hline \multicolumn{7}{|l|}{ Breed } \\
\hline Local & 199 & 1 & 0.5 & $\operatorname{Ref}^{*}$ & - & - \\
\hline Cross & 164 & 4 & 2.4 & 0.1438875 & 0.350 & $0.0024718-8.375796$ \\
\hline Exotic & 17 & 1 & 5.9 & 0.0418366 & 0.180 & $0.0004058-4.313254$ \\
\hline \multicolumn{7}{|l|}{ Body condition } \\
\hline Poor & 108 & 2 & 1.8 & Ref* & -- & - \\
\hline Medium & 181 & 3 & 1.6 & 8.317074 & 0.271 & $0.1912795-361.6369$ \\
\hline Good & 95 & 1 & 1.0 & 6.959143 & 0.348 & $0.1207423-14.0993$ \\
\hline \multicolumn{7}{|c|}{ Management system } \\
\hline Extensive & 146 & 2 & 1.4 & Ref* & - & - \\
\hline Intensive & 11 & 0 & 0.0 & - & - & - \\
\hline Semi-intensive & 227 & 4 & 1.8 & 0.9223248 & 0.953 & $0.061306-13.87602$ \\
\hline \multicolumn{7}{|l|}{ Origin } \\
\hline Born & 273 & 1 & 0.4 & Ref* & - & - \\
\hline Purchased & 111 & 5 & 4.5 & 13.5752 & 0.039 & $1.143753-161.1239$ \\
\hline \multicolumn{7}{|c|}{ Sign of chronic cough } \\
\hline Yes & 85 & 4 & 4.7 & Ref* & - & - \\
\hline No & 299 & 2 & 0.7 & 7.688701 & 0.043 & $0.978141-60.43722$ \\
\hline \multicolumn{7}{|l|}{ Lactation } \\
\hline Lactating & 166 & 4 & 2.4 & Ref* & - & - \\
\hline Non-lactating & 218 & 2 & 0.9 & 0.5209331 & 0.664 & $0.0275714-9.842505$ \\
\hline \multicolumn{7}{|c|}{ Reproductive status } \\
\hline Pregnant & 152 & 1 & 0.7 & Ref* & - & - \\
\hline Non-pregnant & 232 & 5 & 2.0 & 0.3394292 & 0.424 & $0.0240721-4.786132$ \\
\hline
\end{tabular}

Ref $^{*}=$ refers to the reference category 
Asian J. Med. Biol. Res. 2020, 6 (1)

Table 3. Questionnaire survey of the awareness of respondents about the risk factors for the occurrence of bovine TB, feeding habit of animal products, its mode of transmission to humans and history of TB.

\begin{tabular}{|c|c|c|}
\hline Variables & No. of interviewed $(n=107)$ & Percent (\%) \\
\hline To replace their herd those used bull or natural method & 73 & 68.2 \\
\hline To replace their herd those used artificial insemination & 10 & 9.3 \\
\hline To replace herd those purchased from local markets & 21 & 19.6 \\
\hline To replace herd those purchased from research centers & 3 & 2.8 \\
\hline Mix own cattle with others during grazing and watering & 64 & 59.8 \\
\hline Those test their cattle for BTB when purchased & 0.0 & 0.00 \\
\hline Those tested their cattle previously for BTB & 0.0 & 0.00 \\
\hline Sign of chronic cough with progressive wastage of body & 42 & 39.3 \\
\hline Those had the habit of drinking raw milk & 59 & 55.1 \\
\hline Those had the habit of drinking boiled milk & 48 & 48.9 \\
\hline Who understood the side effect of drinking of raw milk & 61 & 57.0 \\
\hline Those had the habit of eating raw meat & 38 & 35.5 \\
\hline Those had the habit of eating cooked meat & 69 & 64.5 \\
\hline Who understood the side effect of eating raw meat & 63 & 58.9 \\
\hline Those heard BTB is a cattle disease and it is zoonotic & 23 & 21.5 \\
\hline Those shared single living house with their cattle & 20 & 18.8 \\
\hline Those know BTB can transmit by prolonged close contact & 21 & 19.6 \\
\hline Those know BTB can transmit by drinking of raw milk & 29 & 27.1 \\
\hline Those know BTB can transmit by eating of raw meat & 25 & 23.4 \\
\hline Those know BTB can transmit by inhalation or via air & 24 & 22.4 \\
\hline Those affected with tuberculosis (TB) & 11 & 10.3 \\
\hline Those affected with HIV/AIDS & 3 & 2.8 \\
\hline HIV/AIDS patients positive for tuberculosis (TB) & 1 & 0.9 \\
\hline
\end{tabular}


Table 4. The influence of respondent's age and educational status on their knowledge of bovine tuberculosis is a cattle disease and it could be a zoonotic disease.

\begin{tabular}{|c|c|c|c|c|c|c|}
\hline Variables & $\begin{array}{l}\text { No. of respon- } \\
\text { dents }(\mathrm{N}=107)\end{array}$ & $\begin{array}{l}\text { Heard BTB is a cattle disease } \\
\text { and it could be zoonotic }\end{array}$ & Percent (\%) & Odds Ratio & P-value & $\begin{array}{l}\text { 95\% CI } \\
\text { (lower and upper limit) }\end{array}$ \\
\hline \multicolumn{7}{|c|}{ (2) } \\
\hline Young & 37 & 12 & 32.4 & $\operatorname{Ref}^{*}$ & - & - \\
\hline Adult & 70 & 11 & 15.7 & 1.2456 & 0.049 & $0.0032756-1.88807$ \\
\hline \multicolumn{7}{|l|}{ Education status } \\
\hline Illiterate & 23 & 4 & 17.4 & 3.15 & 0.168 & $0.616869-16.08526$ \\
\hline Primary school & 39 & 9 & 23.1 & Ref* & - & - \\
\hline Junior school & 9 & 2 & 22.2 & 2.4 & 0.437 & $0.237337-21.84021$ \\
\hline High school & 13 & 4 & 30.8 & 1.65 & 0.559 & $0.3072948-8.859572$ \\
\hline Higher institution & 23 & 10 & 43.5 & 0.466 & 0.183 & $0.1521487-1.431348$ \\
\hline
\end{tabular}

$\mathrm{Ref}^{*}=$ refers to the reference category; $\mathrm{CI}=$ Confidence interval; $\mathrm{N}=$ total number of participants in the questionnaire survey

Table 5. The influence of respondent's age, sex and educational status on their knowledge of the transmission of bovine tuberculosis to human through prolonged close contact with infected cattle.

\begin{tabular}{|c|c|c|c|c|c|c|}
\hline Variables & $\begin{array}{l}\text { No. of respon- } \\
\text { dents }(\mathrm{N}=107)\end{array}$ & $\begin{array}{lcc}\text { knew BTB transmit with } \\
\text { close contact }\end{array}$ & Percent (\%) & Odds Ratio & P-value & $\begin{array}{l}\text { 95\% CI (lower and } \\
\text { upper limit) }\end{array}$ \\
\hline \multicolumn{7}{|r|}{ 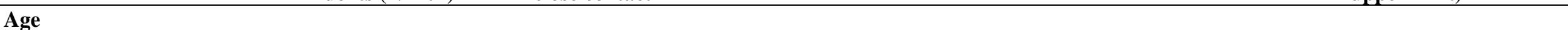 } \\
\hline Young & 37 & 11 & 29.7 & Ref* & - & - \\
\hline Adult & 70 & 10 & 14.3 & 2.2066 & 0.143 & $0.766215-6.35457$ \\
\hline \multicolumn{7}{|l|}{ Sex } \\
\hline Male & 66 & 18 & 27.3 & & & \\
\hline Female & 41 & 11 & 26.8 & 0.82026 & 0.819 & $0.264177-2.86681$ \\
\hline \multicolumn{7}{|l|}{ Education status } \\
\hline Illiterate & 23 & 1 & 4.3 & 6.0198 & 0.107 & $0.679859-53.3012$ \\
\hline Primary school & 39 & 8 & 20.5 & $\operatorname{Ref}^{*}$ & - & - \\
\hline Junior school & 9 & 1 & 11.1 & 2.4166 & 0.515 & $0.223438-19.9192$ \\
\hline High school & 13 & 2 & 15.4 & 1.3974 & 0.705 & $0.2478-7.87969$ \\
\hline Higher institution & 23 & 9 & 39.1 & 0.42967 & 0.182 & $0.12416-1.4869$ \\
\hline
\end{tabular}

Ref $^{*}=$ refers to the reference category; $\mathrm{CI}=$ Confidence interval; $\mathrm{N}=$ total number of participants in the questionnaire survey 
Table 6. The influence of respondent's sex, age and educational status on their awareness of the transmission of bovine tuberculosis to human through consumption of raw milk obtained from tuberculosis infected cattle.

\begin{tabular}{|c|c|c|c|c|c|c|}
\hline Variables & $\begin{array}{l}\text { No. of respon- } \\
\text { dents }(\mathrm{N}=107)\end{array}$ & $\begin{array}{l}\text { known BTB transmit by } \\
\text { drinking of raw milk }\end{array}$ & Proportion (\%) & Odds Ratio & P-value & $\begin{array}{l}\text { 95\% CI (lower and } \\
\text { upper limit) }\end{array}$ \\
\hline \multicolumn{7}{|l|}{ Age } \\
\hline Young & 37 & 12 & 32.4 & Ref* & - & - \\
\hline Adult & 70 & 17 & 24.3 & 1.23821 & 0.653 & $0.48724-3.14674$ \\
\hline \multicolumn{7}{|l|}{ Sex } \\
\hline Male & 66 & 18 & 27.3 & Ref* & & \\
\hline Female & 41 & 11 & 26.8 & 0.69178 & 0.480 & $0.24863-1.9248$ \\
\hline \multicolumn{7}{|l|}{ Education status } \\
\hline Illiterate & 23 & 4 & 17.4 & 1.578698 & 0.506 & $0.410775-6.06728$ \\
\hline Primary school & 39 & 9 & 23.1 & Ref* & - & - \\
\hline Junior school & 9 & 2 & 22.2 & 1.022597 & 0.980 & $0.1779772-5.8755$ \\
\hline High school & 13 & 4 & 30.8 & 0.6278491 & 0.520 & $0.1522679-2.5888$ \\
\hline Higher institution & 23 & 10 & 43.5 & 0.3600664 & 0.09 & $0.110348-1.17489$ \\
\hline
\end{tabular}

Ref*= refers to the reference category; $\mathrm{CI}=$ Confidence interval; $\mathrm{N}=$ total number of participants in the questionnaire survey

Table 7. The influence of respondent's versus their sex, age and educational category on their awareness of the transmission of the bovine tuberculosis to human through inhalation of infective droplets from infected cattle.

\begin{tabular}{|c|c|c|c|c|c|c|}
\hline Variables & $\begin{array}{l}\text { Number of } \\
\text { respondents }(N=107)\end{array}$ & $\begin{array}{l}\text { known BTB transmit via } \\
\text { inhalation }\end{array}$ & Percent (\%) & Odds Ratio & P-value & $\begin{array}{l}95 \% \text { CI } \\
\text { (lower and upper limit) }\end{array}$ \\
\hline \multicolumn{7}{|l|}{ Age } \\
\hline Young & 37 & 11 & 32.4 & Ref* & - & - \\
\hline Adult & 70 & 13 & 24.2 & 1.521886 & 0.420 & $0.54795-4.22688$ \\
\hline \multicolumn{7}{|l|}{ Sex } \\
\hline Male & 66 & 18 & 27.3 & Ref* & - & - \\
\hline Female & 41 & 11 & 26.8 & 0.75278 & 0.625 & $0.241328-2.34821$ \\
\hline \multicolumn{7}{|l|}{ Education status } \\
\hline Illiterate & 23 & 1 & 17.4 & 7.18799 & 0.07 & $0.82411-62.6944$ \\
\hline Primary school & 39 & 9 & 23.1 & Ref* & - & - \\
\hline Junior school & 9 & 3 & 22.2 & 2.37925 & 0.44 & $0.25868-21.8829$ \\
\hline High school & 13 & 1 & 30.8 & 0.94914 & 0.946 & $0.208449-4.32175$ \\
\hline Higher institution & 23 & 10 & 43.5 & 0.38054 & 0.114 & $0.11482-1.26120$ \\
\hline
\end{tabular}

Ref* $^{*}$ refers to the reference category; $\mathrm{CI}=$ Confidence interval; $\mathrm{N}=$ total number of participants in the questionnaire survey 
Table 8. The occurrence and relative prevalence of human tuberculosis recorded in Bonga general hospital from September 1, 2000 to February 30,2006 E.C. (For six and half years).

\begin{tabular}{|c|c|c|c|c|c|c|c|c|c|}
\hline \multirow{2}{*}{$\begin{array}{l}\text { Years } \\
\text { (E.C) }\end{array}$} & \multirow[t]{2}{*}{ Sex } & \multicolumn{2}{|c|}{ *PTB smear cases } & \multirow{2}{*}{$\begin{array}{l}\text { *ETB smear cases } \\
\text { Positive }(\%)\end{array}$} & \multicolumn{2}{|c|}{ All new cases } & \multirow[t]{2}{*}{$\%$ PTB } & \multirow[t]{2}{*}{$\%$ ЕРТВ } & \multirow{2}{*}{$\begin{array}{l}\% \text { PTB } \\
\text { negative }\end{array}$} \\
\hline & & Positive (\%) & Negative (\%) & & In each sex & In both & & & \\
\hline \multirow[t]{2}{*}{2000} & Male & $28(26.4)$ & $37(34.9)$ & $41(38.7)$ & 106 & 223 & 23.3 & 31.8 & 44.8 \\
\hline & Female & $24(20.5)$ & $63(53.8)$ & $30(25.6)$ & 117 & & & & \\
\hline \multirow[t]{2}{*}{2001} & Male & $28(28.3)$ & $47(47.5)$ & $24(24.2)$ & 99 & 187 & 28.9 & 29.4 & 41.7 \\
\hline & Female & $26(29.5)$ & $31(32.2)$ & $31(35.2)$ & 88 & & & & \\
\hline \multirow[t]{2}{*}{2002} & Male & $25(27.7)$ & $41(45.5)$ & $24(26.6)$ & 90 & 151 & 24.5 & 24.5 & 51.0 \\
\hline & Female & $12(19.6)$ & $36(59.0)$ & $13(21.3)$ & 61 & & & & \\
\hline \multirow[t]{2}{*}{2003} & Male & $45(26.3)$ & $92(53.8)$ & $34(19.9)$ & 171 & 297 & 24.2 & 19.9 & 55.9 \\
\hline & Female & $27(21.4)$ & $74(58.7)$ & $25(19.8)$ & 126 & & & & \\
\hline \multirow[t]{2}{*}{2004} & Male & $62(32.8)$ & $87(46.0)$ & $40(21.2)$ & 189 & 341 & 33.4 & 20.2 & 46.3 \\
\hline & Female & $52(34.2)$ & $71(46.7)$ & $29(19.1)$ & 152 & & & & \\
\hline \multirow[t]{2}{*}{2005} & Male & $39(35.8)$ & $60(55.0)$ & $10(9.2)$ & 109 & 203 & 29.1 & 16.2 & 54.7 \\
\hline & Female & $20(21.3)$ & $51(54.2)$ & $23(24.5)$ & 94 & & & & \\
\hline \multirow[t]{2}{*}{2006} & Male & $30(24.2)$ & $77(62.1)$ & 17 (13.7) & 124 & 203 & 26.1 & 10.3 & 63.5 \\
\hline & Female & $23(29.1)$ & $52(65.8)$ & $4(5.1)$ & 79 & & & & \\
\hline Total & & $441(27.5)$ & $819(51.0)$ & 345 (21.5) & 1605 & 1605 & & & \\
\hline
\end{tabular}

*PTB=Pulmonary Tuberculosis; *EPTB=Extra-pulmonary Tuberculosis. 


\section{Conclusions}

The result of the present study has revealed relatively low prevalence of bovine tuberculosis in dairy cattle and poor awareness of the respondents on zoonotic implication of bovine tuberculosis. Secondary data of tuberculosis in human case registered for six and half years in Bonga general hospital showed that a total of 786 smear positive cases for TB, 56\% had pulmonary TB and 44\% had extra pulmonary TB cases. This could be due to poor knowledge of the cattle owners about bovine tuberculosis and its mode of transmissions to human and the feeding habit of raw milk and raw meat of the society. Unrestricted cattle movements were other factor in the area; required to control the spread of this disease by cooperation of farmers, veterinarians, administrative bodies concerned this issue and policy makers involved in planning mitigation measures to control livestock movements. Based on above conclusion the following points are recommended:

$>$ The prevalence of the disease was relatively low, but dairy cattle are kept near dwelling and maintained under very poor management and hygienic status in the study area, thus increasing the risk of acquiring infection for animals and humans as well, so emphasis should be given on controlling the disease before it spreads.

D Test and slaughter policy is impractical in Ethiopia, due to lack of economic capacity to compensate farmers/cattle owners. Therefore, priority should be given for segregation and practice of boiling the milk of infected cattle before selling and consumption at home.

$>$ Unrestricted cattle movements and low awareness of the society about bovine tuberculosis are common in the area. These could favor the transmission of infection from cattle to cattle and to human. So awareness creation should be done for the whole society about bovine tuberculosis and its mode of transmission.

$>$ There should be further detailed investigation of the disease epidemiology and molecular characterization to identify its exact distribution and magnitude in the present study area.

\section{Acknowledgements}

I would particularly like to forward my heartfelt gratitude to my advisor Dr. Belay Abebe, who helped me from early design of the research proposal to the final write-up of the manuscript. In fact, the completion of this work would not have been possible without his guidance, in valuable suggestions, comments, professional expertise, constructive criticisms and devotion of time in correcting this paper. I would like to express my sincere appreciation to Mizan Teferi regional veterinary laboratory and staff members. I got all the materials, including the purified protein derivative antigen from them. I also thank the cattle owners of Bonga town who were willing to be part of the study and provided complete information.

\section{Conflict of interest}

None to declare.

\section{References}

WHO, 1999. Report on the Global HIV/AIDS epidemic. World Health Organization, Geneva; pp. 1-14.

WHO, 1993. Report of World Health Organization meeting on zooonotic TB/M. bovis with the participation of FAO, Geneva; pp. 1-2.

Radostits OM, CC Gay, DC Blood and KW Hinchelift, 2006. Disease caused by bacteria Mycobacterium. In: Veterinary Medicine: A Text Book of Disease of Cattle, Sheep, Pig, Goat and Horses. 10th ed. Harcourt Publisher, London. pp. 1007-114.

Thoen CO, JH Steele and MJ Gilsdorf, 2006. Mycobacterium bovis Infection in Animals and Humans. $2^{\text {nd }}$ ed. Blackwell Publishing Professional, Ames, Iowa, USA. pp. 317.

Amanfu W, 2006. The situation of tuberculosis and tuberculosis control in animals of economic interest. Tuberculosis, 86: 330-335.

Cosivi O, JM Grange, CJ Daborn, MC Raviglione, T Fujikura, D Cousins, RA Robinson, MF Huchzermeyer, I Dekantoe and F Meslin, 1998. Zoonotic tuberculosis due to $M$.bovis in developing countries. J. Emerg. Dis., 4: 59-70.

OIE, 2009. Bovine tuberculosis: (OIE manual of diagnostic tests and vaccines for terrestrial animals OIE, Paris France. Available at: Www.oie.int. Accessed April 14/2014.

Bonsu OA, E Laing and BD Akanmori, 2000. Prevalence of tuberculosis in cattle in the Dangme-West district of Ghana, public health implications. Acta Trop., 76: 9-14.

Grange JM, 1995. Human aspects of Mycobacterium bovis infection. In: Theon, O. C and Steele, H.J (Eds). Mycobacterium bovis infection in animals and humans, Iowa State University Press. pp. 29-46. 
Ameni G, P Cockle, K Lyashchenko and Vordermeier, 2012. T-Cell and Antibody responses to Mycobacterium Antigens in Tuberculin Skin-Test-Positive Bos indicus and Bos taurus cattle in Ethiopia. Veterinary Medicine International, 1-6.

Kafa Zone Agriculture and Rural Development Department, 2012. Kafa Zone Livestock population. Pp: 20-21.

Thrustfield M, 2007. Veterinary Epidemiology. $2^{\text {nd }}$ edition, London, Black well science Ltd. pp. 178-198.

Nicholson MJ and MH Butterworth, 1986. A guide to Body condition score in zebu cattle. International livestock center for Africa, Addis Ababa. pp. 72-74.

OIE, 2004. Bovine tuberculosis: (OIE manual of diagnostic tests and vaccines for terrestrial animals: Mammals, birds and Bees); $5^{\text {th }}$ edn, Volume I. pp. 451-460, Paris, France.

Mananghan ML, JD Collins, JF Kazada and PJ Quinn, 1994. The tuberculin test. Vet. Microbiol., 40: 111-124.

Ameni $\mathrm{G}$ and $\mathrm{G}$ Laval, 2004. Prevalence of bovine tuberculosis in zebu cattle under traditional animal husbandry in Boji district of western Ethiopia. Review Veterinary Medicine, 155: 494-499.

Ameni G and E Erkihun, 2007. Bovine tuberculosis and farmer's awareness on small-scale dairy farms in Adama town. Review on Science and Technology Office of International Epizootics; 26: 3.

Sisay WZ, HR Daniel, GA Atsede and BZ Yibrah, 2013. Detection of human and bovine tuberculosis using an existing diagnostic practice in residential districts of Tigray region, northern Ethiopia. J. Environ. Occup. Sci., 2: 77-88.

Redi N, 2003. Prevalence of bovine tuberculosis and zoonotic implication in Asela town, South East Ethiopia. (DVM. Thesis), Faculty of veterinary medicine, Addis Ababa.

Mamo G, F Abebe, Y Worku, N Hussein, M Legesse, G Tilahun, G Medhin, G Bjune and G Ameni, 2013. Bovine tuberculosis and its associated risk factors in pastoral and agro-pastoral cattle herds of Afar Region, North East Ethiopia. J. Vet. Med., 5: 171-179.

Amenu K, A Regassa and T Macrotty, 2010. Brucellosis and tuberculosis in Arsi-Negele districts in Ethiopia: prevalence in ruminants and people's behavior towards zoonoses. Tropical Culture, 4: 204-210.

Fikre Z, R Gebremedhin, B Gebretsadik, M Gezahegne, S Tesfaye and A Gobena, 2014. Prevalence of bovine tuberculosis and assessment of Cattle owners' awareness on its public health implication in and around Mekele, Northern Ethiopia. J. Vet. Med. Anim. Health, 6: 159-167.

O'reilly LM and CJ Daborn, 1995. The epidemiology of Mycobacterium bovis infections in animal and man. Tuberculosis Lung Disease, 76: 1-16.

Ameni G and G Medhin, 2000. Effect of gastro-intestinal parasitosis on tuberculin test for the diagnosis of BTB. Journal Applied Animal Science, 18: 200-204.

Tamiru F, M Hailemariam and W Terfa, 2013. Preliminary study on prevalence of bovine tuberculosis in cattle owned by tuberculosis positive and negative farmers and assessment of zoonotic awareness in Ambo and Toke Kutaye districts, Ethiopia. J. Vet. Med. Anim. Health, 5: 288-293.

Teschopp R, A Aseffa, E Schelling, S Berg, E Hailu, E Gadisa, M Habtamu, K Argaw and J Zinsstag, 2010. Bovine tuberculosis at the wildlife-livestock-human interface in Hamer Woreda, South Omo, Southern Ethiopia. PLoS One, 5: 12205.

Inangolet FO, D Biffa, J Oloya, J Opuda-Asibo and E Skjerve, 2008. A cross-sectional study of bovine tuberculosis in the transhumance and agro-pastoral cattle herds in the border areas of Katakwi and Moroto districts, Uganda. Trop. Anim. Health Prod., 40: 501.

Barwinnek F and NM Taylor, 1996. Assessment of the socio economic importance of eradication. TurkishGerman Animal Health Information project. General Directorate of Protection and Control. pp. 3-45.

Ameni G, 1996. Bovine tuberculosis: evaluation of diagnostic tests, prevalence and zoonotic importance. [DVM thesis], Faculty of Veterinary Medicine, Addis Ababa university, Debre-Zeit, Ethiopia.

Nega M, H Mazengia and M Mekonen, 2012. Prevalence and zoonotic implications of bovine tuberculosis in Northwest Ethiopia. International Journal of Medicine and Medical Sciences, 2: 188-192.

Asseged B, A Liibke-berker, E Lemma, K Taddele and S Britton, 2000. Bovine tuberculosis: A cross sectional and epidemiological study in and around Addis Ababa. Bulletin of Animal Health and Production in Africa, 48: 71-80.

Kiros T, 1998. Epidemiology and zoonotic importance of bovine tuberculosis in selected sites of East Shewa Ethiopia. [DVM.Thesis], Faculty of Veterinary Medicine, Addis Ababa University, Debre Zeit, Ethiopia.

Ameni G and E Erkihun, 2007. Bovine tuberculosis and farmer's awareness on small-scale dairy farms in Adama town. Review on Science and Technology Office of International Epizootics, 26: 3.

Ashford DA, E Whitney, P Raghunathan and O Cosivi 2001. Epidemiology of selected Mycobacterium that infect humans and other animals. Review of Science and Technology, Office International des Epizootics, 20: $325-337$. 
Kleeberg HH, 1984. Human tuberculosis of bovine origin in relation to public health. Review of Science and Technology, Office of International des Epizooties, 3: 11-32.

Ameni G and A Wudie, 2003. Preliminary study of bovine tuberculosis in Nazerath municipality abattoir of central Ethiopia. Bulletin of Animal Health and Production for Africa; 51: 125-132.

Ameni G, K Amenu and M Tibbo, 2003a. Bovine Tuberculosis: Prevalence and Risk Factor assessment in cattle and cattle owners in Wuchale-Jida District, Central Ethiopia. International Journal Research in Veterinary Medicine, 1: 17-25.

Lee K and A Mills, 2000. Strengthening governances for global health research: the countries must need health research should decide what should be funded. Br. Med. J., 321: 775-776.

Tirsit K, B Deressa, A Fana and W Tigre, 2013. Farmers awareness on rabies, bovine TB, Taeniasis, Haydatidosis and Brucellosis in Mana and Limmu-kuso Districts of Jimma zone, South west Ethiopia. World Appl. Sci. J., 23: 782-787.

Tigre W, G Alemayehu, T Abeto and B Deressa, 2011. Priliminary study on public health Implication of Bovine tuberculosis in Jimma town, South western Ethiopia. Global Veterinary, 6: 369-373.

Munyeme M, BJ Muma, MH Munang'andu, C Kankya, E Skjerve and M Tryland, 2010. Cattle owners' awareness of bovine tuberculosis in high and low prevalence settings of the wildlife-livestock interface areas in Zambia. Vet. Res., 6: 4-6.

Ndukum JA, AC Kudi, G Bradley, IN Ane-Anyangwe, S Fon-Tebug and J Tchoumboue, 2010. Prevalence of bovine tuberculosis in abattoirs of the Littoral and Western Highland Regions of Cameroon: A cause for Public Health Concern. Vet. Med. Int., 10: 4061-4072.

Grange JM, 1995. Human aspects of Mycobacterium bovis infection. In: Theon, O. C and Steele, H.J (Eds). Mycobacterium bovis infection in animals and humans, Iowa State University Press. pp. 29-46.

WHO, 2005. Global tuberculosis control surveillance. Planning and Financing. WHO Report, Country Profile, Ethiopia, 83-86.

Assefa A, H Engers, D Young, G Hewinson and M Vrdermier, 2006. Cattle husbandry in Ethiopia is a predominant factor affecting the pathology of $B T B$ and Gamma interferon responses Mycobacterium antigens. Clinical Vaccines and Immunology, 13: 1030-1336. 